\title{
CONTINUES PROCESS IMPROVEMENT DENGAN SIX SIGMA PADA PROSES PRODUKSI CaO
}

\author{
Deny Andesta \\ Program Studi Teknik Industri - Fakultas Teknik \\ Universitas Muhammadiyah Gresik
}

\begin{abstract}
ABSTRAKSI
PT. Giri Mulya Jatim adalah perusahaan yang memproduksi kapur aktif ( $\mathrm{CaO}$ ) untuk industri. Perusahaan menghadapi kendala pada kualitas $\mathrm{CaO}$ yang dihasilkan dari proses pembakaran batu kapur ( $\left.\mathrm{CaCO}_{3}\right)$, berupa cacat mayor berupa batu curing sebesar 5\% dan defect minor yang merupakan jenis cacat kritis dan terdiri dari kadar persentase CaO dibawah standar sebesar 45.6\%, Insuluble Meter (28.4\%) dan ukuran butir (26\%). Penelitian ini mengaplikasikan pendekatan six sigma dengan satu siklus DMAIC. Faktor yang dominan yang teridentifikasi sebagai penyebab ketidaksesuaian persentase kadar $\mathrm{CaO}$ adalah jenis bahan bakar, ukuran batu kapur dan jenis batu kapur. Terjadi perubahan nilai DPMO dan level sigma antara kondisi sebelum penelitian dan sesudah tahap improve. DPMO naik dari 37.133 menjadi 41.667. Sedangkan level sigma turun dari 3,3 menjadi 3,2.
\end{abstract}

Kata kunci : Six Sigma, DMAIC, CaO, Level Sigma.

\section{PENDAHULUAN}

Kehidupan sebuah produk dimulai dari sebuah kebutuhan yang berasal dari konsumen (voice of customer), diproduksi, dan siap dipergunakan melewati berbagai tahapan-tahapan seperti perancangan, produksi, testing, dipasarkan, dikembangkan, dan akhir dari kehidupan produk (recycle dan dibuang). Agar dapat diterima oleh konsumen, perusahaan berusaha melakukan pengembangan produk secara berkelanjutan (sustainable) (Gumus, 2005).

Pengembangan produk sebagai suatu proses, bukanlah suatu kegiatan yang berdiri sendiri dan bersifat rutin mekanistik, tetapi merupakan suatu kegiatan yang mencakup berbagai fungsi yang ada dalam perusahaan dan memerlukan berbagai fungsi yang ada dalam perusahaan dan memerlukan pola pikir yang kreatif dari segenap pelaksananya. Peranan pengembangan produk ini sangat memerlukan kelangsungan hidup suatu perusahaan.

Dengan kompleknya system yang ada dalam dunia industri, menimbulkan berbagai persoalan, seperti keterbatasan sumber daya manusia, material, biaya produksi, pengaturan produksi, dan berbagai hal lainnya. Salah satu persoalan utama dalam industri adalah bagaimana cara menciptakan produk yang murah dan berkualitas, dengan mengoperasikan sistem produksi secara efisien agar diperoleh biaya produksi rendah. Untuk menjaga citra yang baik pada pangsa pasarnya, maka setiap perusahaan berusaha untuk memunculkan produk yang dapat diterima pasar, dengan melakukan perubahanperubahan pada produk atau dengan memenuhi keinginan konsumen.

Para analis bisnis akan setuju bahwa dalam rangka untuk tetap bertahan pada pasar, perusahaan harus mengantisipasi pelanggan, dengan meningkatkan efficiency and 
effectiveness pada proses dalam rangka penurunan ongkos produksi serta sedang menuju standar mutu yang tinggi (Gilbert, 2003).

Pengawasan terhadap produk mutlak diimplementasikan sebagai jaminan pada konsumen bahwa produk yang dilemparkan ke pasaran memiliki mutu yang baik. Proses Quality Control dimulai pada saat bahan baku masuk gudang sampai proses yang terjadi pada tiap bagian di lantai produksi. Kualitas adalah derajat keseragaman dan kepercayaan, pada biaya yang rendah dan sesuai dengan pasar (Howard. G, 1995, Gitlow, 1987). Perusahaan harus secara kontinyu memenuhi spesifikasi produk yang memenuhi permintaan konsumen. Perbaikan proses untuk meningkatkan kualitas akan memberikan manfaat seperti : mengurangi rework, meningkatkan produktivitas, menekan biaya produksi per-unit, meningkatkan posisi yang kompetitif di pasar, dan profit yang lebih besar. Loss quality terjadi ketika proses menghasilkan produk dengan kualitas yang tidak dapat diramalkan keseragamannya, yaitu terdapat variasi yang tinggi dari unit-unit produk yang dibuat.

Usaha meningkatkan kualitas produk dapat dilakukan dengan menerapkan pendekatan Six Sigma yang mempunyai siklus DMAIC (Define, Measure, Analyze, Improve, dan Control). Six Sigma merupakan suatu methodologi yang sistematik, yang merupakan suatu utilizes tools, training dan alat ukur pada organiasi dalam merancang produk dan proses untuk menyesuaikan harapan konsumen serta dapat menghasilkan tingkatan kualitas six sigma (Mader, 2002). Six sigma dapat meningkatkan pengembangan produk baru dan sistem proses pengembangan, mengurangi resiko penggunaan tool seperti pandangan penggunaan tool kuantitative dan mengukur pengembangan berdasarkan proses untuk mengurangi atau menghilangkan kebutuhan subjektivitas (Hayes, 2003).

Perubahan batu kapur (Calcium Carbonate) menjadi quick lime $(\mathrm{CaO})$ dilakukan dengan proses kalsinasi atau pembakaran, sudah dikenal sejak dulu (Krumnacher, 2001) dan sudah dikenal luas oleh masyarakat kita sebagai bahan untuk pengapuran yang memberikan warna putih.

Kebutuhan kapur aktif $(\mathrm{CaO})$ pada industri sangat banyak (consumable) sehingga unit produksi kapur harus meningkatkan produksinya untuk memenuhui kebutuhan pasar serta meningkatkan kualitas produknya agar dapat bersaing dengan produk kapur yang lain.

Untuk mendapatkan calcium carbonate dilakukan dengan cara menambang dan diproses secara tradisional. Ini sudah banyak dilakukan di berbagai daerah penghasil batu kapur. Kendala dalam memproduksi kapur secara tradisional adalah kualitas $\mathrm{CaO}$, seperti kadar kapur aktif tidak bisa maksimal dan masih banyak terjadi defect berupa batuan curing, yang harus dipisahkan karena batuan curing merupakan batuan yang diambil dari tambang pada bagian permukaan dan juga terbentuk karena proses yang tidak sempurna sehingga tidak dapat diproses lebih lanjut. Disamping itu, kapasitas produksi yang rendah antara 25 - 30 ton per 5 hari, dan juga dari sumber daya manusianya kurang mampu dalam memproses yang lebih efektif dan efisien, sehingga banyak terjadinya cacat (defect). 


\section{Perumusan Masalah}

Dari permasalahan diatas, maka dapat dijelaskan bahwa permasalahan tersebut dapat dirumuskan yaitu Bagaimana melakukan perbaikan proses yang berkesinambungan dengan Six Sigma pada kualitas produk CaO (quick Lime)?.

\section{Tujuan Penelitian}

Berdasarkan latar belakang masalah yang telah dijelaskan, maka tujuan yang akan dicapai dalam pelaksanaan penelitian ini, antara lain :

1. Mengidentifikasi jenis defect penyebab ketidak sesuaian pada produk kapur aktif pada proses produksi $\mathrm{CaO}$ ?

2. Mengidentifikasi faktor dominan penyebab ketidak sesuaian kandungan produk $\mathrm{CaO}$.

3. Menetukan setting parameter yang tepat sehingga dapat mengoptimalkan kualitas $\mathrm{CaO}$.

\section{TINJAUAN PUSTAKA \\ Six Sigma}

Sigma $(\sigma)$ adalah sebuah abjad Yunani yang menotasikan standar deviasi suatu proses. Standar deviasi mengukur variasi atau jumlah persebaran suatu rata-rata proses. Dengan kata lain, sigma merupakan unit pengukuran statistik yang mendeskripsikan distribusi tentang nilai rata-rata (mean) dari setiap proses atau prosedur. Suatu proses atau prosedur yang dapat mencapai lebih atau kurang kapabilitas Six Sigma dapat diharapkan memiliki tingkat cacat yang tidak lebih dari beberapa ppm (parts per million), meskipun mengizinkan untuk beberapa pergeseran dalam nilai rata-rata (mean). Dalam terminologi statistika, ini mencapai kegagalan nol (zero defects).

Tingkat kualitas sigma biasanya juga dipakai untuk menggambarkan variasi dari suatu proses. Semakin tinggi tingkat sigma maka semakin kecil toleransi yang diberikan pada kecacatan dan semakin tinggi kemampuan proses. Sehingga variasi yang dihasilkan semakin rendah dan dapat mengurangi frekuensi munculnya defect, biayabiaya proses, waktu siklus proses mengalami penurunan dan kepuasan customer meningkat. (Gaspersz,2002).

Pada dasarnya pelanggan akan puas jika mereka menerima nilai sebagaimana yang mereka harapkan. Apabila produk diproses pada tingkat kualitas Six Sigma, perusahaan boleh mengharapkan 3,4 kegagalan per sejuta kesempatan atau mengharapkan bahwa 99,99966 persen dari apa yang diharapkan pelanggan akan ada dalam produk tersebut. Dengan demikian Six Sigma dapat dijadikan ukuran target kinerja sistem industri tentang bagaimana baiknya suatu proses transaksi produk antara pemasok (industri) dan pelanggan (pasar). Semakin tinggi target sigma yang dicapai, kinerja sistem industri akan semakin baik. Sehingga 6-sigma otomatis lebih baik daripada 4-sigma, 4-sigma lebih baik dari 3-sigma. Six Sigma juga dapat dipandang sebagai pengendalian proses industri berfokus pada pelanggan, melalui penekanan pada kemampuan proses (process capability). 


\section{Batu Kapur (Limestone)}

Kapur banyak mengandung unsur Calsium Carbonate secara spesifik berwarna putih, abu - abu kuning tua, abu - abu kebiruan, jingga dan sedikit kehitaman, yang mempunyai berat jenis 2,6 - 2,8 dalam keadaan murni berbentuk kristal kalsit. Untuk mendapatkan calcium carbonate dilakukan dengan cara menambang dan diproses secara tradisional. Ini sudah banyak dilakukan di berbagai daerah penghasil batu kapur yang tersebar di berbagai daerah di Indonesia dan dipergunakan sebagai bahan baku untuk pembuatan semen.. Batu kapur dapat dibedakan atas cara proses yang dilakukan untuk mendapatkan hasil akhir seperti gambar 1. siklus lime (Krumnacher,2001):

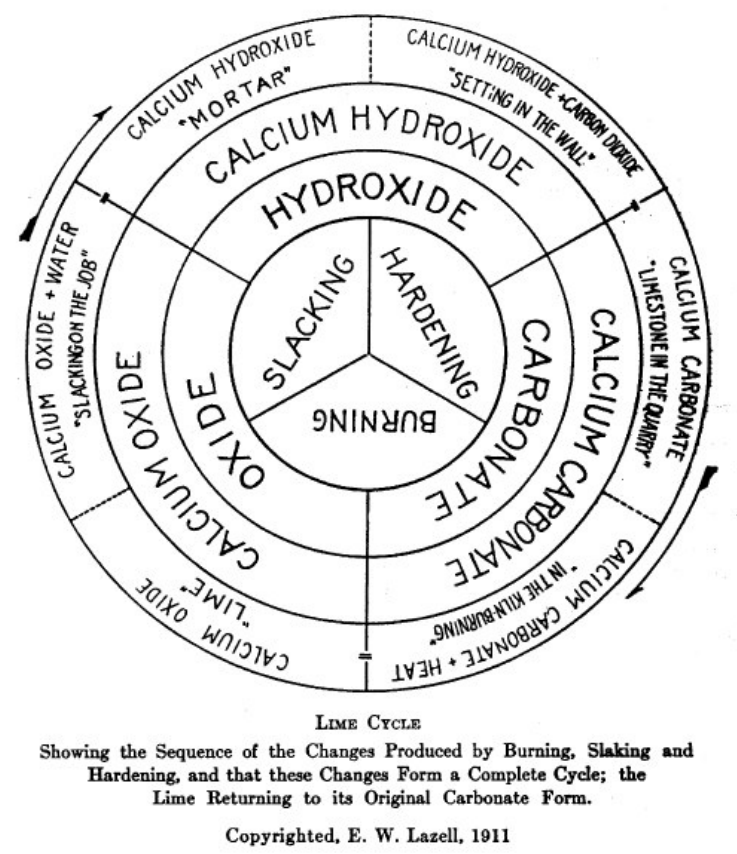

Gambar 1. Lime Cycle

\section{METODOLOGI PENELITIAN}

Aliran kegiatan yang dilakukan dalam penelitian ini dibagi atas empat tahapan yang terbagi seperti di bawah ini : 


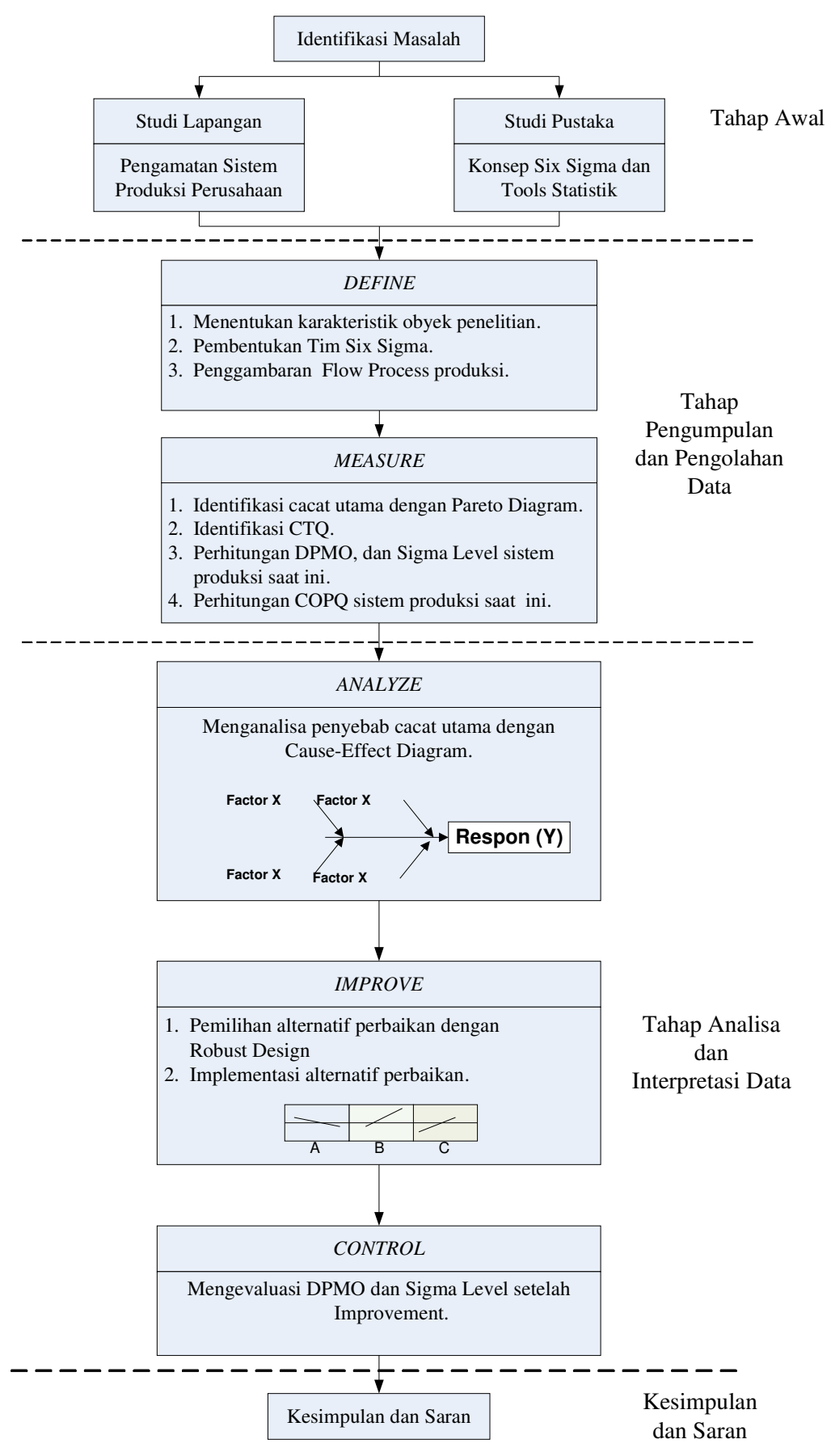

Gambar 2. Flowchart metodologi penelitian 


\section{PEMBAHASAN}

\section{Define}

Define merupakan langkah pertama dari siklus DMAIC dalam program peningkatan kualitas dengan Six Sigma.

\section{Identifikasi Kriteria Pemilihan Proyek}

Produk yang dihasilkan oleh PT. Giri Mulya Jatim adalah kapur aktif. Kapur aktif $(\mathrm{CaO})$ dihasilkan dari proses pembakaran batu kapur (Calcium Carbonat atau $\mathrm{CaCo}_{3}$ ). Defect yang teridentifikasi dari proses pembakaran tersebut adalah defect mayor dan defect minor.

Defect mayor berupa batu curing dan berdasarkan hasil pengamatan dan wawancara pada periode Februari - April 2006 diperoleh hasil batu curing sebesar 5\% dari total batu kapur yang dibakar per proses.

Defect minor ditemukan pada $\mathrm{CaO}$ hasil pembakaran. Type defect minor yang teridentifikasi berupa kosentrasi $\mathrm{CaO}$ yang dibawah standar, Insoluble Meter (IM) terlalu tinggi dan butiran.

Berdasarkan hasil sampling terhadap produk akhir selama periode Februari April 2006, dari 5000 sampel ditemukan 557 cacat minor yaitu :

$\checkmark 254$ sampel mengandung cacat kosentrasi yang dibawah standar (45.6\%).

$\checkmark 145$ sampel terdapat cacat IM (28.4\%).

$\checkmark 158$ sampel mempunyai cacat butir (26\%).

Defect yang terjadi pada proses pembakaran batu kapur baik mayor maupun minor, sama-sama harus diminimalkan. Dalam penelitian ini akan difokuskan pada defect minor yang dapat terjadi pada semua type pembakaran yang dipergunakan, baik system burner dengan bahan bakar cair atau tradisional.

\section{Identifikasi Flow Proses}

Identifikasi flow proses merupakan salah satu alat Six Sigma yang paling esensial dalam mendokumentasikan proses. Secara keseluruhan flow proses pembuatan produk $\mathrm{CaO}$ dimulai dari proses pengambilan bahan baku pada tambang Batu Kapur sampai dengan pengantongan dan penyimpanan dapat dilihat dalam gambar 4.2

Penyusunan batu kapur di dalam tungku merupakan langkah penting untuk terlaksananya proses pembakaran yang efisien dan merata ke seluruh umpan batu kapur yang akan dibakar sehingga seluruhnya terkalsinasi menjadi $\mathrm{CaO}$.

Di bagian dasar disusun batu kapur berukuran besar 20- $30 \mathrm{~cm}$ x 30-40 cm. Susunan ini berfungsi sebagai fondasi untuk menopang susunan batu kapur selanjutnya sampai ke bagian atas tungku agar pada saat pembakaran tidak longsor atau jatuh dikarenakan penataan tidak sempurna dan itu dibutuhkan tenaga ahli yang sudah terbiasa melakukan hal tersebut. Untuk penataan dalam kapasitas 25 - 30 ton dibutuhkan waktu $1-2$ hari baru dilakukan persiapan untuk pembakaran. 

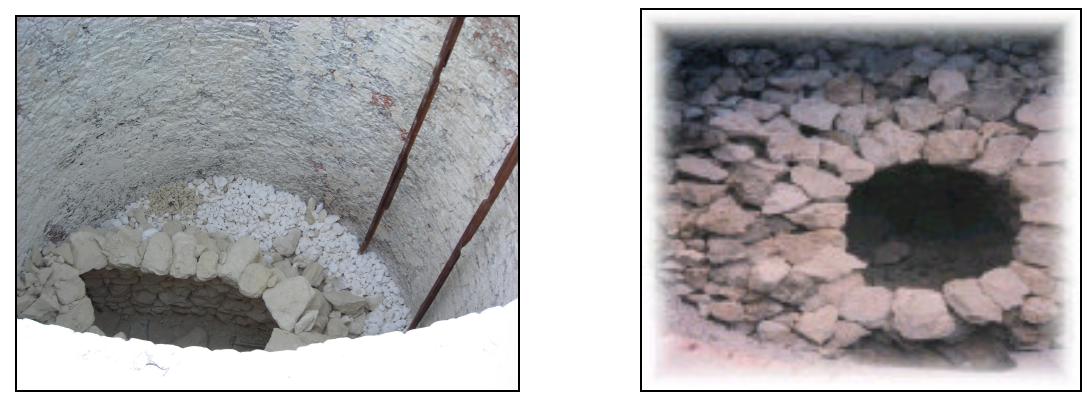

Gambar 3. Proses Penyusunan Batu Kapur

Pembakaran dimulai dengan api kecil menggunakan kayu bakar untuk mengeringkan batu kapur. Api dapat dibesarkan setelah batu kapur hampir kering sehingga uap air tidak terlalu banyak. Banyaknya uap air akan mengganggu draft (tarikan) sehingga pembakaran kurang lancar, banyak menghasilkan jelaga yang mengganggu proses pembakaran selanjutnya.

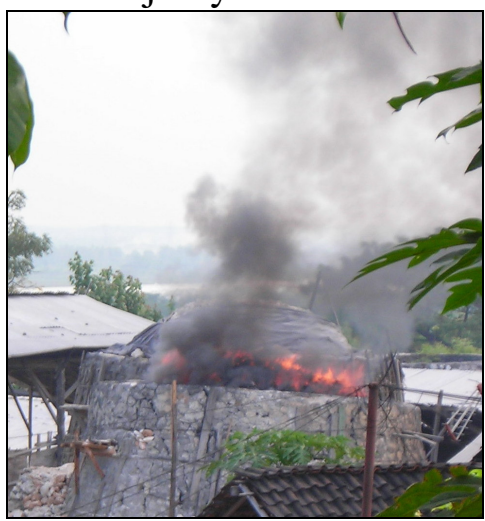

Gambar 4. Proses Pembakaran Batu Kapur

Proses pembakaran membutuhkan minimal satu orang untuk menjaga agar proses tetap berlangsung sampai terjadinya pembakaran sempurna, untuk terjadinya pembakaran sempurna membutuhkan waktu 5-6 hari. Setelah pembakaran selesai dibiarkan 1 hari untuk proses pendinginan setelah itu dilakukan pembongkaran dengan memilih batu kapur yang sudah terkalsinasi dengan batu kapur yang masih mentah / tidak bisa diproses (batu Curing). Setelah proses pembongkaran di lanjutkan proses penggilingan, sebelum penggilingan dilakukan pemecahan dari batu besar dipecah menjadi kecil - kecil sesuai yang dikehendaki untuk mempermudah proses penggilingan juga dilakukan set up mesin giling sesuai permintaan konsumen termasuk ukuran ayakan yang dikehendaki, apabila dalam proses terdapat butiran yang tidak sesuai dilakukan proses penggilingan ulang dan seterusnya.

Proses pengantongan dengan cara manual dengan menggunakan alat timbang yang kapasitasnya besar untuk satu kantong / bag kapur aktif beratnya $50 \mathrm{~kg}$ sedang kantong didalamnya diberi inert (plastik tipis) kedap udara agar konsentrasi kapur aktif tidak turun dikarenakan kelembaban udara. Setelah proses pengantongan produk dikirim ke gudang penyimpanan dan siap di kirim ke konsumen. 


\section{Measure}

Measure adalah tahap kedua dalam siklus DMAIC.

\section{Identifikasi Karakteristik Kritis Terhadap Kualitas ( CTQ )}

Six Sigma yang difokuskan pada cacat dan variasi, dimulai dengan mengidentifikasi unsur-unsur kritis terhadap kualitas (CTQ) dari produk $\mathrm{CaO}$ sebagai berikut :

$\begin{array}{lll}\text { 1. } & \text { Kandungan } \mathrm{CaO} \text { aktif } & \min : 65 \% \\ \text { 2. } & \text { Insuluble Meter (IM) } & \max : 2 \% \\ \text { 3. } & \text { Ukuran butiran (Size) } & \min : 90 \%\end{array}$

\section{Identifikasi Defect Minor Pada Hasil Proses Produksi}

Seperti yang telah dijelaskan pada sub bab pertama bahwa yang akan diperbaiki adalah kapur aktif yang memiliki jenis defect minor. Identifikasi defect minor tersebut dilakukan pada produk akhir. Dikarenakan perusahaan PT. Giri Mulya Jatim sudah tidak memiliki lagi laboratorium pengukuran maka hasil defect minor didasarkan pada report / informasi dari konsumen (PT. Petrokimia Gresik) sesuai dengan spesifikasi yang ditetapkan seperti kandungan $\mathrm{CaO}$ aktif, Insuluble Meter dan Ukuran butiran (size) selama bulan Februari - April 2006 yang telah teridentifikasi sebagai berikut:

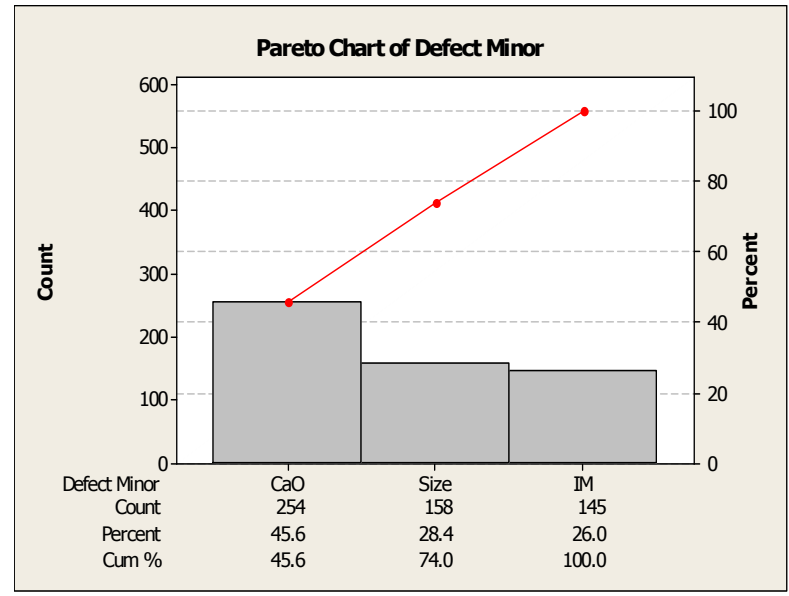

Gambar 5. Pareto Chart Defect Minor

\section{Mengukur Baseline Kinerja (Performance Baseline)}

Pengukuran baseline kinerja dilakukan untuk mengetahui tingkat kinerja selama 3 bulan, sehingga dapat ditetapkan target yang ingin dicapai berupa penurunan defect $\mathrm{CaO}$. Baseline kinerja dalam penelitian ini menggunakan satuan pengukuran DPMO (Defect Per Million Opportunities) sebesar 37133 dan kapabilitas Sigma 3,285.

\section{Cost of Poor Quality (COPQ)}

Penurunan kualitas produk $\mathrm{CaO}$ menimbulkan biaya-biaya. Biaya-biaya tersebut muncul karena kerugian atas biaya produksi yang telah dikeluarkan untuk 
unit-unit produk yang ditolak. Pada kasus produk $\mathrm{CaO}$ terdapat dua macam biaya yang harus ditanggung oleh PT Giri Mulya Jatim sebagai akibat adanya penurunan kualitas, yaitu :

1. Biaya sampling kualitas $\mathrm{CaO}$.

2. Biaya proses rework yang harus dikeluarkan.

Berdasarkan rekapan 3 bulan terakhir maka dapat di jelaskan dibawah :

Tabel 1. Penghitungan Defect kedalam COPQ

\begin{tabular}{|c|c|c|c|c|c|c|c|}
\hline No & Defect & $\begin{array}{c}\text { Kuantitas } \\
\text { Inspeksi }\end{array}$ & $\begin{array}{c}\text { Kuantitas } \\
\text { Defect }\end{array}$ & DPMO & Sigma & COPQ & $\begin{array}{c}\text { Persentase } \\
(\%)\end{array}$ \\
\hline 1 & $\mathrm{CaO}$ Aktif & \multirow{4}{*}{5000} & 254 & 16933.3333 & 3.622 & 76200000 & 5.08 \\
\hline 2 & Ukuran butiran (Size) & & 158 & 10533.3333 & 3.807 & 47400000 & 3.16 \\
\hline 3 & Insuluble Meter (IM) & & 145 & 9666.66667 & 3.839 & 43500000 & 2.9 \\
\hline & Proses & & 557 & 37133.3333 & 3.285 & 167100000 & 11.14 \\
\hline
\end{tabular}

\section{ANALYZE}

\section{Identifikasi Sumber-Sumber Dan Akar Penyebab Masalah Defect Minor CaO}

Untuk mengatasi cacat-cacat yang tergolong sebagai CTQ maka faktor-faktor penyebab munculnya cacat-cacat tersebut distrukturkan dalam bentuk fish bone diagram. Fish bone diagram dibentuk melalui pengamatan di lapangan dan diskusi di antara anggota tim six sigma. Berdasarkan hasil brainstorming tersebut maka didapatkan sumber dan akar penyebab dari masalah defect minor $\mathrm{CaO}$, serta mendapatkan solusi masalah yang efectif dan efisien. Jenis cacat yang akan dianalisa adalah cacat kadar $\mathrm{CaO}$, IM dan butir yang terjadi pada proses produksi.

\section{Cacat kadar $\mathrm{CaO}$}

Batu kapur dapat terjadi dengan beberapa cara, yaitu secara organik, secara mekanik, atau secara kimia. Sebagian besar batu kapur yang terdapat di alam terjadi secara organik, jenis ini berasal dari pengendapan cangkang/rumah kerang dan siput, foraminifera atau ganggang, atau berasal dari kerangka binatang koral/kerang. Batu kapur dapat berwarna putih susu, abu muda, abu tua, coklat bahkan hitam, tergantung keberadaan mineral pengotornya.

Cacat kadar $\mathrm{CaO}$ dapat dipengaruhi oleh pemilihan material awal batu kapur yang tidak diuji laboratorium terlebih dahulu walau rata-rata kandungan yang terdapat pada daerah penambangan sebesar $30-89 \%$ kalsium $(\mathrm{Ca})$, akan tetapi belum tentu homogen. Komposisi kimia batu kapur sangat bervariasi pada tiap daerah dan cadangannya (P.S. Dwivedi, 2004). Material yang dipergunakan oleh perusahaan terdiri dari atas dua jenis batu kapur yang dilihat secara visual terdiri atas dua jenis yaitu : berwarna putih dan putih kekuningan. Disamping itu dapat terjadi pada proses pembakaran batu kapur yang tidak sempurna. 


\section{Cacat IM}

Pengotoran yang terjadi pada $\mathrm{CaO}$ dapat berakibat pada meningkatnya IM karena $\mathrm{CaCO}_{3}$ yang ada dialam tidaklah murni. Selain dari pengotoran, dapat juga terjadi dalam proses itu sendiri yang berupa material yang tidak berubah menjadi $\mathrm{CaO}$, sehingga berpengaruh ketika digiling dan diayak, masih tetap ada. Berdasarkan hasil pengamatan dan wawancara dengan pihak yang terlibat, cacat IM juga disebabkan oleh faktor dari operator yang kurang hati-hati dalam melakukan proses sehingga tercampur dengan abu hasil pembakaran atau tanah.

\section{Cacat butir}

Ukuran butir yang diinginkan konsumen sebesar mesh 100 dan dari pengamatan pada periode Februari - April 2006 mempunyai cacat yang paling kecil dibandingkan jenis cacat yang lainnya. Type cacat butir ini disebabkan oleh pembakaran dan penggilingan pada proses produksi. Pada proses produksi terjadi secara microstruktur dari pembentukan $\mathrm{CaO}$ itu sendiri. Tegangan yang terjadi pada material yang terbakar memberi pengaruh perubahan struktur dari $\mathrm{CaCO}_{3}$ menjadi $\mathrm{CaO}$ dan $\mathrm{CO}_{2}$, perubahan ini tidaklah stabil karena $\mathrm{CaO}$ bersifat tidak stabil, dapat berubah menjadi stabil ketika tercampur dengan air dan menjadi kapur mati. Ketika perubahan material inilah, yang menentukan ukuran butir pada $\mathrm{CaO}$. Selain itu juga dapat terjadi pada proses penggilingan dan penggayakan yang disebabkan alat penggayakan yang tidak sesuai kebutuhan serta tercampur dengan ukuran lainnya.

\section{IMPROVE}

\section{Menetapkan Variabel Respon}

Berdasarkan CTQ yang ada, maka dapat dirumuskan karakteristik kualitas yang digunakan. Karakteristik kualitas kadar $\mathrm{CaO}$ dan butir adalah Large The Better (LTB) sehingga semakin tinggi kadar dan kehalusan butiran semakin baik kualitasnya, sedangkan IM adalah Small The Better (STB), semakin kecil IM semakin bagus $\mathrm{CaO}$. Karakteristik kualitas yang dijadikan tujuan perbaikan dalam penelitian ini adalah kadar $\mathrm{CaO}$, berdasarkan diagram pareto, jenis cacat yang terbesar yaitu 45,6\%.

\section{Menetapkan Variabel Bebas}

Varibel-variabel yang terlibat dalam eksperimen ini, berdasarkan pengamatan dan wawancara, serta diagram sebab akibat yang terdiri dari faktor yang terkontrol (control factor) dan faktor yang tidak dapat dikontrol (noise faktor) serta levelnya. Pemilihan level pada masing-masing faktor terkendali dilakukan berdasarkan metode yang sekarang digunakan oleh para pengusaha batu kapur di Jatim.

\section{Control Faktor}

Variabel bebas atau faktor terkendali yang berpengaruh terhadap kualitas $\mathrm{CaO}$ adalah sebagai berikut :

a. Jenis batu kapur (Faktor A) yang dipergunakan yang terdiri dari dua jenis yaitu :

i. Batu kapur berwarna putih (Level 1) 
ii. Batu kapur berwarna putih kekuningan (Level 2)

b. Ukuran batu kapur (Faktor B) yang akan dibakar yaitu :

i. $2-5 \mathrm{~cm}$ (kecil), (Level 1)

ii. $6-10 \mathrm{~cm}$ (sedang), (Level 2)

c. Jenis bahan bakar (Faktor C) yang dipergunakan dalam proses pembakaran

i. Kayu dan batok kelapa (Level 1)

Noise Faktor

ii. Kayu dan batubara (6000 kkal/kg), (Level 2)

Variabel yang tidak dapat dikendalikan yang berpengaruh kepada kualitas $\mathrm{CaO}$, adalah sebagai berikut :

a. Jenis pembakaran yang dilakukan (Faktor N1)

i. Dibawah susunan batu kapur (Level 1)

ii. Diatas susunan batu kapur (Level 2)

b. Temperatur udara lingkungan (Faktor N2)

i. Diatas $32^{\circ} \mathrm{C}$ (Level 1)

ii. Dibawah $32^{0} \mathrm{C}$ (Level 2)

c. Kelembaban (Faktor N3)

i. Diatas $56 \%$ (Level 1)

ii. Dibawah 56\% (Level 2)

\section{Kombinasi Level Optimum dan Prediksi S/N Ratio}

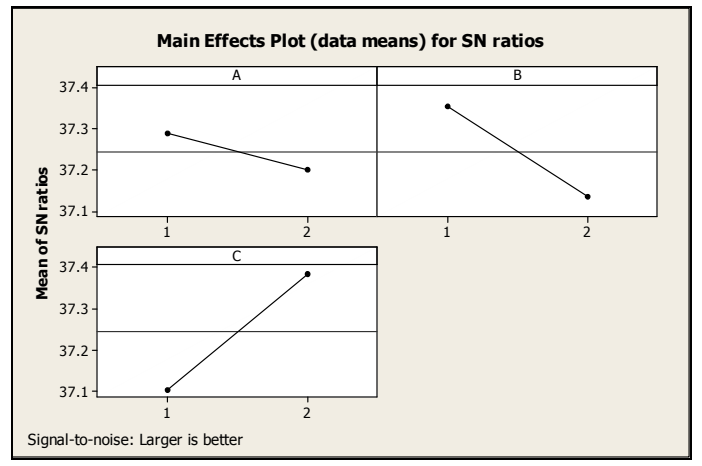

Gambar 6. Plot Pengaruh Faktor Utama Respon $\mathrm{CaO}$ 


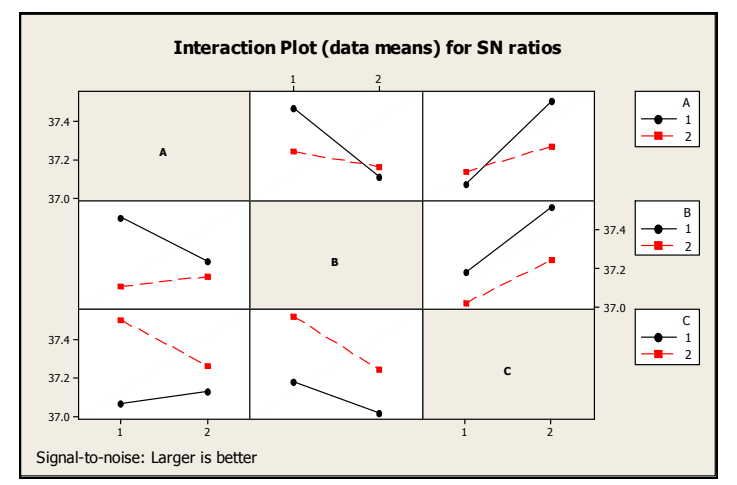

Gambar 7. Plot Pengaruh Interaksi antar Faktor Utama pada $\mathrm{CaO}$

Faktor-faktor yang signifikan yaitu ukuran batu kapur $\left(\mathrm{B}_{2}\right)$, jenis bahan bakar $\left(\mathrm{C}_{2}\right)$, interaksi jenis batu kapur dan ukuran batu kapur $(\mathrm{AxB})$, dan jenis batu kapur dan jenis bahan bakar $(\mathrm{AxC})$ sehingga untuk respon kadar $\mathrm{CaO}$,

\section{Eksperimen Konfirmasi}

Percobaan konfirmasi bertujuan untuk membuktikan apakah faktor atau level optimum yang diperoleh dari percobaan utama dapat mengoptimalkan respon kadar $\mathrm{CaO}$. Pada percobaan konfirmasi untuk respon respon kadar $\mathrm{CaO}$ dilakukan 4 kali pengulangan dengan 2 kali pengujian. Hasil percobaan konfirmasi ditabelkan sebagai berikut :

Tabel 2. Percobaan Konfirmasi.

\begin{tabular}{|c|c|c|c|c|}
\hline Respon & $\begin{array}{c}\text { Kondisi Optimal } \\
\text { Awal } \mathrm{A}_{1} \mathrm{~B}_{1} \mathrm{C}_{2}\end{array}$ & CI Konfirmasi & $\begin{array}{c}\text { Kondisi Optimal } \\
\text { Percobaan } \mathrm{A}_{1} \mathrm{~B}_{1} \mathrm{C}_{2}\end{array}$ & Peningkatan \\
\hline $\begin{array}{c}\text { Persentase } \\
\text { kadar } \\
\mathrm{CaO}\end{array}$ & $\begin{array}{c}\mathrm{S} / \mathrm{N} \text { opt. }=-37,28 \\
\mathrm{MSD}=0,000187\end{array}$ & $-37,28 \pm 0,887$ & $\begin{array}{c}\text { S/N opt. }=-37,57 \\
\mathrm{MSD}=0.067523\end{array}$ & 0,29 \\
\hline
\end{tabular}

Dari tabel 5.13 di atas terlihat kondisi optimum percobaan menghasilkan peningkatan nilai $\mathrm{S} / \mathrm{N}$ terhadap respon kadar $\mathrm{CaO}$ dibandingkan dengan kondisi optimum perusahaan (awal).

Karena hasil dari percobaan konfirmasi untuk respon kadar $\mathrm{CaO}$ terletak pada selang kepercayaan di atas, dapat disimpulkan bahwa faktor dan level yang dihasilkan pada percobaan utama telah sesuai dengan apa yang diharapkan.

\section{CONTROL}

Control adalah tahap ketiga dalam siklus DMAIC. Tahap ini berfokus untuk menyusun dan mengimplementasikan sebuah mekanisme kontrol untuk menghindari munculnya cacat yang dikategorikan sebagai Crititical To Quality agar tidak muncul kembali.

\section{Mekanisme kontrol}


Untuk menghindari munculnya cacat perlu dilakukan pengontrolan terhadap kualitas $\mathrm{CaO}$. Pada saat ini perusahaan belum menerapkan quality kontrol pada proses pembakaran batu kapur disebabkan oleh minimnya SDM oleh karena itu untuk implementasi kontrol dalam bentuk ceksheet tidak dapat diterapkan.

\section{Perhitungan Kapasitas Proses}

Kapasitas produksi berdasarkan percobaan yang dilakukan dari 250gr batu kapur menghasilkan 84 gr batu curing dan 92.96 gr CaO. Besarnya defek mayor dalam percobaan ini adalah 33,6 \% dan hal ini disebabkan kurang standarnya tungku yang dipergunakan. Berdasarkan pengamatan dan wawancara dengan pihak perusahaan, bahwa kapasitas produksi untuk 100 ton batu kapur, menghasilkan 56 ton $\mathrm{CaO}$.

\section{Perhitungan Level Sigma}

Implementasi perbaikan untuk meningkatkan kualitas $\mathrm{CaO}$ harus dievaluasi untuk mengetahui perubahan nilai DPMO, dan level sigma. Dari hasil uji konfirmasi produksi $\mathrm{CaO}$ dengan 8 replikasi.

Terjadi perubahan nilai DPMO dan level sigma antara kondisi sebelum penelitian dan sesudah tahap improve. DPMO naik dari 37.133 menjadi 41.667. Sedangkan level sigma turun dari 3,3 menjadi 3,2. Hal ini disebabkan belum dilakukanya improve ke dalam perusahaan dan sedikitnya jumlah unit yang diinspeksi.

\section{KESIMPULAN}

Kesimpulan yang dapat ditarik dari penelitian ini ialah :

1. Terdapat dua jenis cacat yang diidentifikasi pada produk $\mathrm{CaO}$ yang dihasilkan oleh PT. Giri Mulya Jatim pada proses pembakaran $\mathrm{CaCO}_{3}$ berupa defect mayor yang berupa batu curing sebesar 5\% dari batu kapur yang dibakar dan defect minor yang terdiri dari 5000 sampel ditemukan :

a. Kadar persentase $\mathrm{CaO}$ yang dibawah standar sebesar $45.6 \%$ dari 254 sampling.

b. Insoluble Meter (IM) sebesar 28.4\% dari 158 sampling.

c. Ukuran butir (Size) sebesar $26 \%$ dari 145 sampling.

2. Faktor dominan yang teridentifikasi sebagai penyebab ketidaksesuaian kandungan $\mathrm{CaO}$ berupa jenis batu kapur, ukuran batu kapur dan jenis bahan bakar yang dipergunakan. Faktor yang berpengaruh secara signifikan terhadap respon persentase kadar $\mathrm{CaO}$ pada percobaan utama adalah jenis bahan bakar berupa campuran kayu dan batubara $\left(\mathrm{C}_{2}\right)$, ukuran batu kapur yang dibakar dengan ukuran kecil $\left(\mathrm{B}_{1}\right)$, interaksi antara jenis batu kapur putih dan ukuran batu kapur $\left(\mathrm{A}_{2} \mathrm{~B}_{1}\right)$, interaksi antara jenis batu kapur putih dan jenis bahan bakar $\left(\mathrm{A}_{2} \mathrm{C}_{2}\right)$.

3. Kondisi optimum untuk respon persentase kadar $\mathrm{CaO}$ dicapai pada kombinasi level $\mathrm{A}_{1} \mathrm{~B}_{1} \mathrm{C}_{2}$ yaitu :

a. Jenis batu kapur (A) : bewarna putih

b. Ukuran batu kapur (B) : kecil $(2-5 \mathrm{~cm})$

c. Jenis bahan bakar (C) : kayu dan batubara (6000 kkal/kg) 
4. Terjadi perubahan nilai DPMO dan level sigma antara kondisi sebelum penelitian dan sesudah tahap improve. DPMO naik dari 37.133 menjadi 41.667. Sedangkan level sigma turun dari 3,3 menjadi 3,2. Hal ini disebabkan belum dilakukanya improve ke dalam perusahaan dan sedikitnya jumlah unit yang diinspeksi.

\section{DAFTAR PUSTAKA}

Allen, D. T., and R. S. Butner, (Nov. 2002), "Industrial Ecology: A Chemical Engineering Challenge," Chem. Eng. Prog., 98(11).

Bar, Neil., et all, (2004), "Sustainability Module 8.5", Presentation for: ESD.60 Lean/Six Sigma Systems MIT Leaders for Manufacturing Program (LFM).

Belavendram,N., (1991), Quality by Desaign : Taguchi Techniques for Industrial Exsperimentation, Prentice Hall, New York.

Benyus, J., (1997), “Biomimicry”, William and Morrow, New York.

Bhavik R. Bakshi and Joseph Fiksel, (2003), "The Quest for Sustainability: Challenges for Process Systems Engineering", halaman 1350 June 2003 Vol. 49, No. 6 AIChE Journal

Bijl, M. et all, (Nov 2004), EU Market Survey 2004 Timber and Timber Products Compiled for CBI by: ProFound.

Carnegie, Kashonia L., Howard Nielsen, Colin Glover , (2000), Stepping upstream 'naturally' for cleaner production through community environmental learning, Journal of Cleaner Production 8.

Conner, Gary L., (Dec 2003), Moisture Susceptibility of Bottom Ash Asphalt Mixes, Thesis, University of Wyoming.

Fiksel, J., (Fall 2000), "Measuring Sustainability in Eco-Design," Sustainable Solutions: Developing Products and Services for the Future, M. Charter and U. Tischner, eds., Greenleaf Publishing, Sheffield, U.K.

Fiksel, J., (2003), "Revealing the Value of Sustainable Development," Corporate Strategy Today, VII/VIII.

Fiksel, J., (2002), "Sustainable Development through Industrial Ecology," Advancing Sustainability through Green Chemistry and Engineering, R. L. Lankey and P. T. Anastas, eds., American Chemical Society, Washington, DC.

Gale, Robert, (2005), Environmental management accounting as a reflexive modernization strategy in cleaner production, Journal of Cleaner Production xx.

Gaspersz, Prof. Dr. Vincent, D.Sc., CFPIM, CIQA (2002). Pedoman Implementasi Program Six Sigma Terintegrasi dengan ISO 9001:2000, MBNQA, Dan HACCP. Edisi pertama. Penerbit PT Gramedia Pustaka Utama, Jakarta.

Giadina, (2006), " Lean Six Sigma and Sustainability“, http://proceedings.ndia.org /JSEM2006/ Wednesday/ Giardina.pdf.

Gitlow, H.S. and S.J. Gitlow., (1987), The Deming guide to quality and competitive position, Prentice-Hall, Inc. Newark, NJ.

G. Howard, A. Oppenheim, R. oppenheim (1995). Quality Management Tools and Methods for Improvement. $2^{\text {nd }}$ Edition. Irwin Inc, Chicago. 
Gumus, Bulent., (Dec 2005), Requirements Traceability (RT) Throughout the System Using Axiomatic Product Development Lifecycle, Dissertation, Texas Tech University.

Hayes, B. J., (2003), Improving offshore outsourcing efficiency with DFSS. Accessed at: http://software.isixsigma.com/library/content/c031112a.asp.

Kjaerheim, Gudolf., (2005), Cleaner production and sustainability Journal of Cleaner Production 13.

Krumnacher, Paul J.,(2001), Lime and Cement Technology: Transition from Traditional to Standardized Treatment Methods, Thesis, Faculty of the Virginia Polytechnic Institute and State University.

Mader, D. M. (2002), Design for Six Sigma. Quality Progress, July, 82-86.

Mullins, G.L.,(2005) , Sources of Lime for Acid Soils in Virginia, Produced by Agriculture and Extension Communications, Virginia Tech.

Black, Peter E., (2005), Ecological Sustainability: A New Look at an Old Paradigm Journal of Ecological Anthropology halaman 76 Vol. 9.

Pyzdek, Thomas (2002). The Six Sigma Handbook Panduan Lengkap untuk Greenbelts, Blackbelts, dan Manajer pada Semua Tingkat. Edisi Pertama. Penerbit Salemba Empat, Jakarta.

Richard G. Little, (2004), Tending the Infrastructure Commons:Ensuring the Sustainability of Our Vital Public Systems International Workshop on Integrated Life-Cycle Management of Infrastructures December 9-11, 2004 The Hong Kong University of Science and Technology Hong Kong SAR, PRC

Rittenhouse, D., (March 2003), "Piecing Together a Sustainable Development Strategy," Chem. Eng. Prog., 99(3), 32.

Roberts, F., P. Kandhal, E. Brown, D. Lee, and T. Kennedy (1996). Hot Mix Asphalt Materials, Mixture Design, and Construction. 2nd edition. Lanham, Maryland: NAPA Education Foundation.

Robèrt, K. H., (1997), The Natural Step: A Framework for Achieving Sustainability in Our Organizations, Pegasus, Cambridge, MA .

Ross,Philip J., (1996), Taguchi Techniques for Quality Engineering, McGraw-Hill.2 ${ }^{\text {nd }}$ ed., New York.

Saling, P., et al., (2002), "Eco-Efficiency Analysis by BASF: The Method," Int. J. of Life Cycle Assessment.

Smith, Purpose of Stabilization Typical Stabilizers Soil Stabilization, Modification http://ceprofs.tamu.edu/smith/SmithSpring418-04/CVEN418Lect24-0402.pdf

UNEP. (1993), Cleaner Production Worldwide. UNEP report, United Nations Environment Programme.

Verfaillie, H. A., and R. Bidwell, (2000), "Measuring Eco-Efficiency: A Guide to Reporting Company Performance," WBCSD, Geneva.

Wang Hongtao, (2001), "Introduction of the course", Industrial Ecology HongtaoCollege of Material Science and Engineering, Sichuan University, Chengdu, China.

WBCSD, (2002), Toward a Sustainable Cement Industry, Battelle Memorial Institute. 